\title{
Test and Application of Magnetic Survey in Detecting Ancient Wooden Sunken Boats
}

\author{
Mingsong $\mathrm{Qi}^{1}$, Fei Cheng ${ }^{1}$, Weimin $\mathrm{Lu}^{2}$,Aimei $\mathrm{Ma}^{2}$, Chuanlei Wang ${ }^{1,3^{*}}$ \\ ${ }^{1}$ Institute of Geophysics and Geomatics \\ China University of Geosciences \\ Wuhan, China \\ ${ }^{2}$ Cultural Relic Management Section of Juan County, \\ Heze, Shandong \\ ${ }^{3}$ Geology Science and Engineering Section, Wuhan University of Engineering Science, Wuhan, China \\ 1076229599@qq.com
}

\begin{abstract}
There are rich cultural heritages both underwater and in land in China, which is the object concerned by archaeologists and historic researchers, especially the ancient wooden sunken boats containing the past information of old human civlilization we can restore. Detections for buried magnetic massive metals and cement boats with magnetometry have been well perfected technically, but detection for wooden sunken boats has been seldom reported so far. This paper not only confirms that wooden boats can cause magnetic field variation, but also determines the property of field sources and preliminarily estimates the scale and buried depth of them, by means of the test and analysis to magnetic field caused by actual wooden boats. It is shown that detection ancient wooden boat with magnetic survey is feasible, reliable and effective. Finally, this paper introduces examples of detection boats with magnetic survey and briefly discusses the applicable conditions of detection ancient wooden boats with magnetometry, which can be used as reference for archaeologists.
\end{abstract}

Keywords-wooden boat; magnetic field measurement; model test; field source estimation; application effect

\section{INTRODUCTION}

There have been many successful living examples using magnetic method to explore metal-material and wooden sunken boats under the water, and the detecting result has been proven dependable. Besides, this detection technology has won the national patent, and creating a method to successfully detecting underwater magnetic object by using the magnetometer ${ }^{[1-7]}$.

For underwater archaeology, the real valuable object which containing the history-load, antique-value significant is the ancient wooden sunken boat rather than the latter-day metal sunken boat or the concrete boat. Therefore, how to detect the underwater wooden sunken boat by using the magnetic method has been has drown attention by underwater archaeologists and also been an effort direction by the geophysicist.

Due to the material characteristics of metal sunken boats and concrete boats, they can been easily detected by the magnetometer. As for the wooden boat detection, first we need to figure out whether the wooden boat can cause the magnetic field variation or not, then we should ascertain the field source causing this magnetic field variation. Certainly, the maximum depth of the magnetic detection to the wooden boat is also concerned by the researchers. The test and application of detecting wooden sunken boat by the magnetic method is the key point of this paper.

\section{Physical Model Test and Result Analysis of DETECTING WOODEN SUNKEN BOAT BY MAGNETIC METHOD}

The most direct validation technique to test whether magnetic method can be used in detecting wooden sunken boat is model test, by using the magnetometer to measure around a wooden boat and check the magnetic field variation(magnetic anomaly).

\section{A. Introduction to Wooden Boat Physical Model Experiment}

Fig. 1 is the magnetic anomaly plane contour map of the testing result to a 11 metres long, 4 meters wide abandoned wooden boat by using magnetic method, located on the sea beach of Beidaihe.

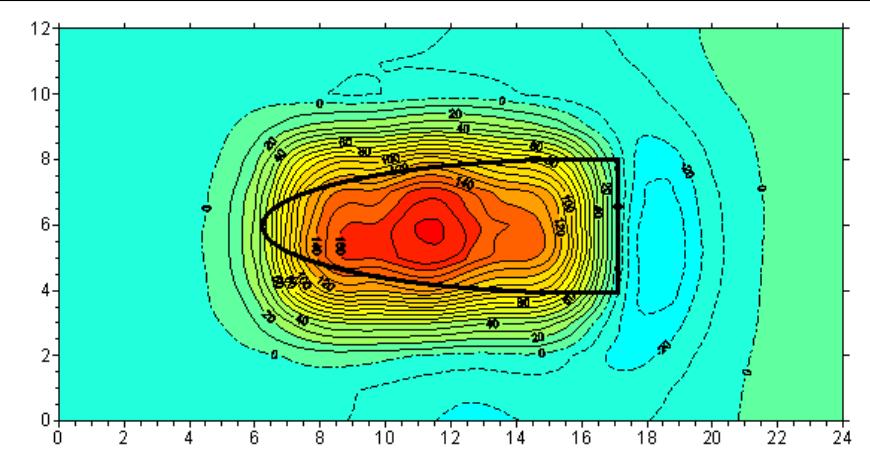

Fig.1. Abandoned wooden fishing boat magnetic anomaly contour map. The blue arc said wooden position. Contour strength unit graph: nT,coordinate numerical units: meters, hereinafter the same. 
We used GEM-19T proton magnetometer to conduct this experiment, and the probe height had been kept around 0.5 meters above the boat deck. Survey density is $2 \times 1 \mathrm{~m} 2$, survey line was paralleled to the long axis of the boat, observation accuracy was less than $\pm 2.0 \mathrm{nT}$. There were no additional iron objects inside the wooden boat, and also no human disturbance near the testing location, magnetic field was steady.

As is shown in the figure, the plus and minus extreme value of the magnetic anomaly respectively are $186 n \mathrm{n}$ and $-37 \mathrm{nT}$, amplitude undergoing is about $223 \mathrm{nT}$. The magnetic anomaly form is regular, long axis direction is obviously seen and have an excellent correspondence to the wooden boat. So we can find and confirm that wooden boat can cause a strong enough magnetic field around itself ,based on magnetic field intensity, magnetic anomaly form and the correspondence between magnetic anomaly and field source. The experiment was satisfactory and obtained desired results.

\section{B. The Magnetic Anomaly Field Source of Wooden Boat}

As we know, wood material is not magnetic, through observation we confirm that the magnetic field source of the wooden boat is the joint element like iron forcer when building the boat. The survey and magnetic susceptibility measurement statistics of the under-repairing Yuan dynasty ancient sunken boat shown in Heze museum(more than 700 years ago)(as shown in Fig.2) and the Qing dynasty sunken boat (more than 100 years ago)which was discovered in Fenghuang village of Juancheng county tells us that the magnetic susceptibility of different ages joint elements are basically similar, and the quantity and scale of those joint elements when building the boat is more than we expected. Such as the repaired Yuan dynasty ancient sunken ship shown in Heze museum, the ship is 21 meters long, 3.4 meters wide, 1.8 meters high, and has 11 compartments. The distribution of iron claws is quite concentrate, the interval is about $13-15 \mathrm{~cm}$, each of the claws is $22 \mathrm{~cm}$ long, $1.2 \mathrm{~cm}$ wide(thinner on both ends), $0.8 \mathrm{~cm}$ thick(as shown in Fig.3). There are 4000-4100 iron claws on this ship as we estimated, if we lay these claws on the ground, the area is almost equivalent to a table tennis table.
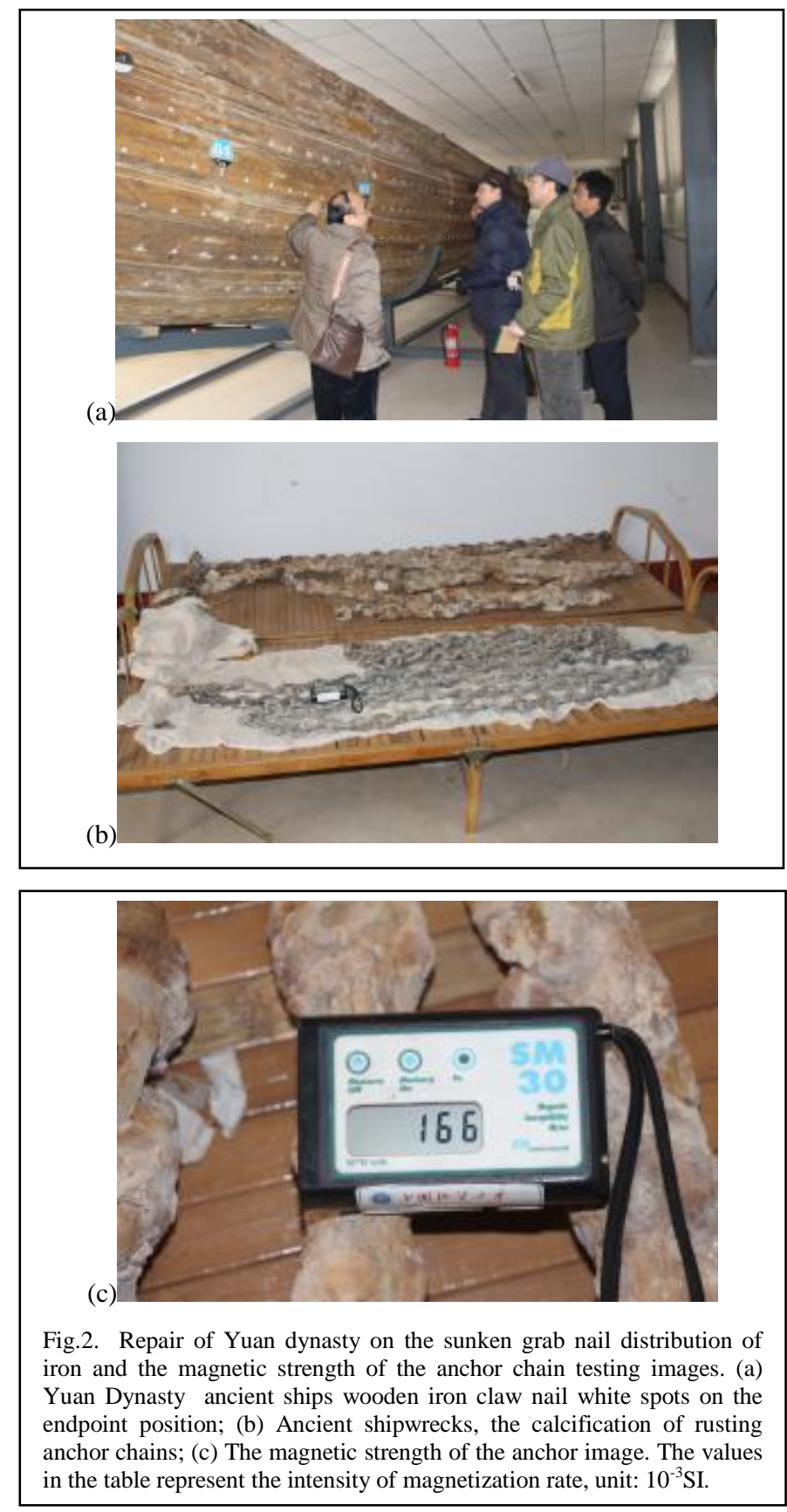


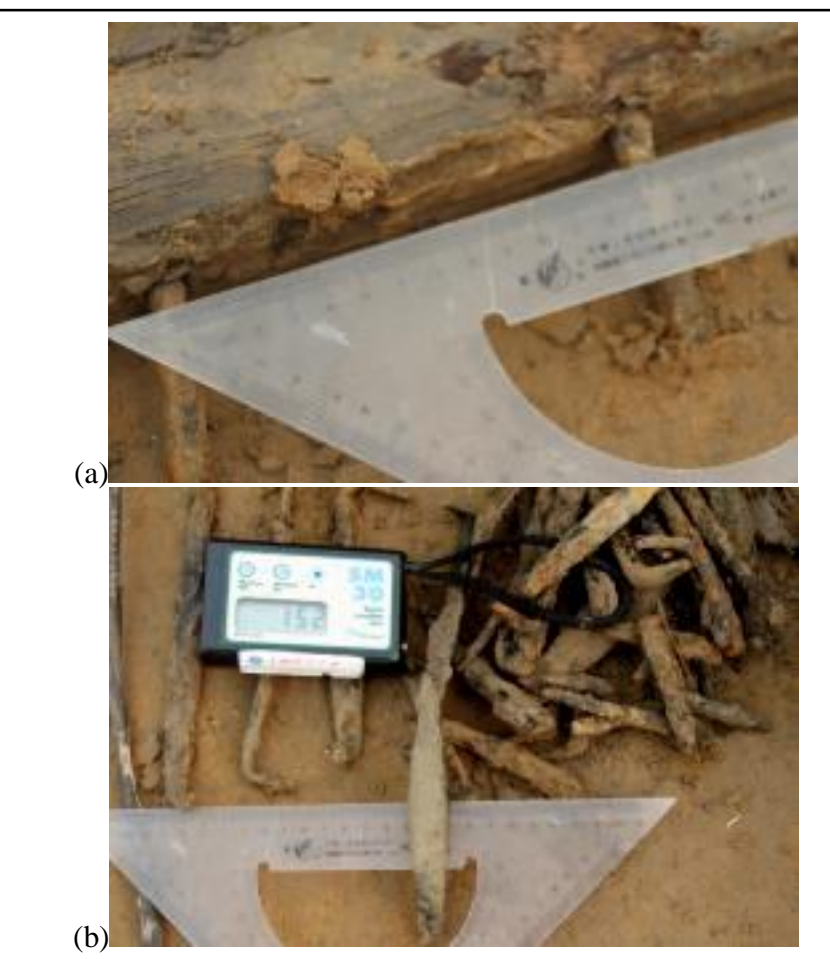

Fig.3. Phoenix Xiang ancient shipwreck on the iron claw nail distribution(a), specifications and magnetic strength test image (b) .The values in the table represent the intensity of magnetization rate, unit: 10-3SI.

Therefor we can say the reason why the wooden sunken ship can cause magnetic field variations surrounding itself are those quantity indispensable strong magnetism iron claws when building the ship. This can provide the geophysical precondition for detecting the ancient wooden wreck with magnetic method.

\section{The APPLICATION EXAMPLE OF DETECTING WoOdEN WRECK BY MAGNETIC METHOD}

The work area of magnetic survey is located in the farmland in northeast coast of Yuzhuang village, Hongchuan town, Juancheng county, Heze city. In the 1950s, someone discovered some boat deck and lumpy black cargoes when digging the cellars, due to the obstruction of underground water and quicksand, the digging was not able to carry on. After more than half a century, the village has gone through several external expansions, people can hardly remember the exact location of the area, they just have a general impression.

The axle wire of the Magnetic archaeological survey work area is determined on the basis of the recalls of many senior villagers who witnessed the scene. The interval of the survey line is $2 \mathrm{~m}$, survey point interval is $1 \mathrm{~m}$ and the magnetometer height is $0.5 \mathrm{~m}$, the total surveying area is $2400 \mathrm{~m} 2$. As the area is close to the village, the disturbance of domestic buildings and transformers made the survey area anomaly.

The processed magnetic anomaly contour map of the survey area is shown in Fig. 4.

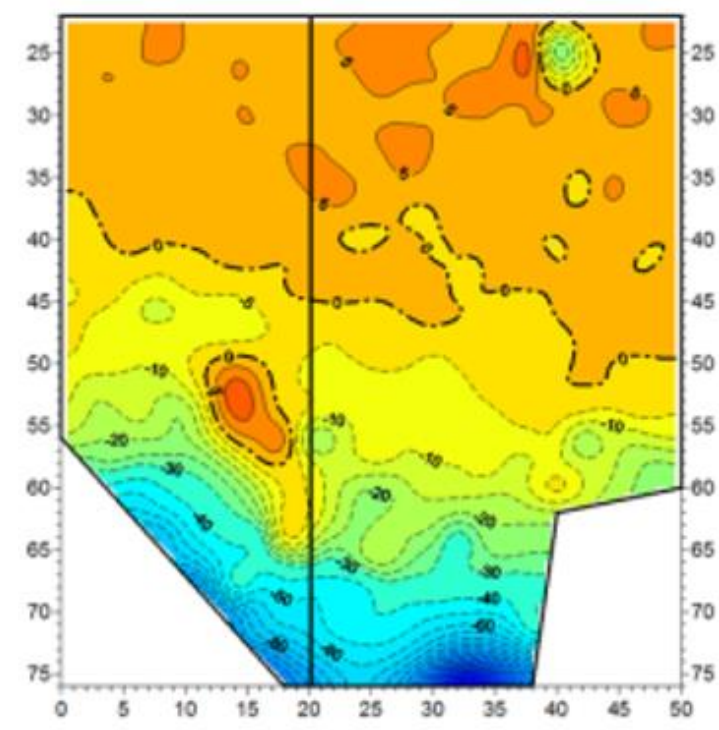

Fig.4. The magnetic anomaly contour map of the survey area in Lizhuang village, Hongchuan town(the thick line on the map is the axis wire of this area).

After studying the magnetic field variation and characteristics of this area, we can see that the magnetic field variation is relatively small and basically steady. There are some negative value contour lines in the southern tip of the survey area, between line 48 and line 64 in the central part of the survey area there is a Northwest strike prolate elliptic magnetic anomaly distribution in the area from measure point 10 to point 20 , the long axis of the magnetic anomaly is about $15 \mathrm{~m}$, the minor axis is about $4 \mathrm{~m}$, the maximum value is greater than $12 \mathrm{nT}$, the shape of the anomaly is regular. In the northern part of the survey area there are several apparent-equiaxial closed contours, and the magnetic anomaly amplitude of point 42 in line 25 is relatively great. As we analyzed on the basis of the magnetic anomaly characteristics of the wreck and situations in the field, those negative value contour lines shown in the southern tip of the survey area is caused by the transformers which is not far away; and those apparentequiaxial closed contours shown in the northern part of the survey area do not possess the magnetic anomaly characteristics of the wreck. The approached prolate elliptic magnetic anomaly distributed in the central part of the map is provided with the magnetic anomaly feature of the wreck, it can be caused by the object we focused on. Besides, the location of this anomaly is roughly the same place which is told by the local villagers, merely has a little discrepancy on the strike. So we can confirm the magnetic anomaly is created by the ancient sunken ship buried in the ground which was discovered by the villager. Therefor we put forwarded a shovel prospecting suggestion, gave an interpretation result(the wreck is 15 meters long, 4 meters wide and buried 3.2 meters below the surface) and an advice for shovel prospecting survey line and hole location.

Through the further conversion and processing for the magnetic data, we obtained the magnetic anomaly maps of the survey area under different conditions, among those maps the magnetic anomaly contour map which is processed with trend 
analysis is the most valuable one(as shown in Fig.5). Form the central part to the north tip of the map, there is an approached east-west strike negative magnetic anomaly band, on the basis that Heze has been part of the Yellow river basin many times in history, we consider this to be band is the reflection of a paleochannel. Because of the later deposited materials have a magnetic difference from the original sediment, it caused a banding magnetic anomaly. Meanwhile it can also explain why the ancient sunken boat is discovered in a modern flat farmland, that's because there had been a river in this place, so the ancient boat can be sailed here.

On April, 2014, Cultural Relics Management Institute of Juancheng county, Heze, Shandong province organized personnel to conduct shovel prospecting verification at this location according to the magnetic prospecting work advice, the verification results indicate that there do have a wreck below this position. The southern tip of the sunken boat is closest to the surface, the distance is about $2.8 \mathrm{~m}$, the deepest spot is at the north part, about $4.1 \mathrm{~m}$, the average buried depth is $3.6 \mathrm{~m}$, the wreck is 15 meters long, 3.1 meters wide. The verification working site is shown in Fig. 6.

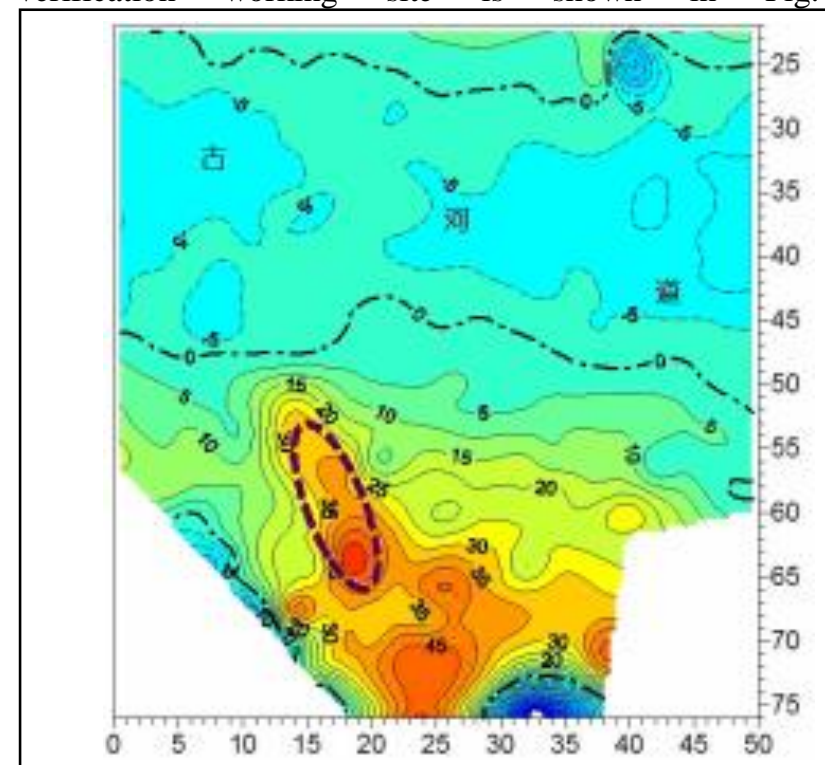

Fig.5. The trend analyzed magnetic anomaly contour map of the survey area in Lizhuang village, Hongchuan town(the oval line shows the location of the wreck).

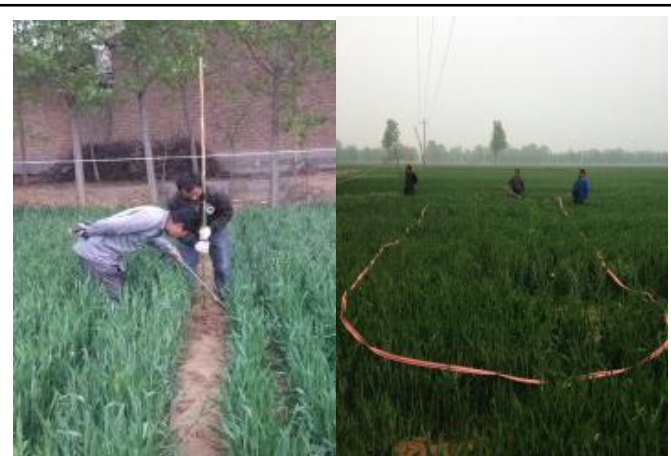

Fig.6. Site photos of shovel prospecting verification in Lizhuang village, Hongchuan town. The yellow tape indicates the range of the wreck according to the verification result.

\section{CONCLUSION}

This paper shows that it is effective to detect wooden sunken boat with magnetic prospecting method. We theoretically verified the feasibility of this method by indicating the geophysical conditions, through wooden boat model test and physical investigation on an ancient wreck and finally we get this result in the practical detection. This paper put forward a new method technology for geophysical prospecting method applied in archaeology investigation, and also opened up a new field for geophysical prospecting applications.

\section{ACKNOWLEDGMENT}

Persons in this work include Lu Weiming, Ma Aimei, Wang Chuanlei, Qi Mingsong, Xie Xueming, Shen Yu, Wang Shaopeng, Wang Hongsong, etc. Thanks to the concern and support from the museum of Heze and Cultural Relics Management Institute of Juancheng county for our experiment, we won't be able to insight the structure and magnetic field source size of ancient wooden boats without their warm reception.

\section{REFERENCES}

[1] Wang C, Qi M, Chen C, et al. Application of High Precision Magnetometry in Sunk Ships at Madang Fort of Yangzi River[J]. Geological Science and Technology Information, 2000, 19 (3): 98-102.

[2] Wang C, Qi M, Qu Z. Geophysical Investigation of Sunken Ships[J]. Archaeology of Jianghan, 2005 (1): 79-82.

[3] Wang C, Qu Z, Qi M, et al. The Magnetic Detection of Sunken Ships in Madang Section of the Yangtze river[J]. Journal of Environmental \& Engineering Geophysics, 2006, 11(2): 123-131.

[4] Li C, Song X, Li J, et al. High Precision Magnetometry Survey Using in the Yangtze River Ship Positioning [C]. the 22th Geophysical Society of China,2006: 1 .

[5] Wang C, Xiao F, Qi M. The Archeology Magnetic Investigation Laoyemiao Water Area, Poyang Lake[C]. the 60th celebration of IGG, China University of Geosciences press, Wuhan , 2012. 5.

[6] Wang C, Shen B, Qi M, et al. Data Acquisition System with Magnetometry Using in Inland and Offshore Waters[P]. CN, 2009 Utility Model Patent, ZL2009 2 0230273. X. 2010. 09. 15.

[7] Wang C, Huang P, Qu Z, Yu Z. Detection and Pinpointing to the Lost Objects in Water Area with Magnetometry[J]. Chinese Journal of Engineering Geophysics, 2009 (S1): 54-58 